\title{
Pengembangan Website Edukasi Interaktif Pengenalan Kesehatan Mental Bagi Remaja
}

\author{
Adam Fauzan Rachmadyanshah ${ }^{a}$ Yuyun Khairunisa ${ }^{b}$ \\ ${ }^{a, b}$ Politeknik Negeri Media Kreatif
}

\section{INFORMASI ARTIKEL}

Diterbitkan Online : 15 Juli 2019

\begin{tabular}{l} 
KATA KUNCI \\
\hline Website Interaktif \\
Kesehatan Mental \\
Edukasi \\
KORESPONDENSI \\
\hline
\end{tabular}

Email : fauzan12.af@gmail.com

Email : yuyun.khairunnisa@gmail.com

\section{A B $\mathbf{S}$ T $\mathbf{R}$ A $\mathbf{C}$ T}

Kesehatan mental adalah sebuah kondisi dimana individu yang terbebas dari berbagai bentuk gejala-gejala gangguan mental. Jika kesehatan mentalnya terganggu, maka suasana hatinya akan terganggu, sulit berpikir dan kendali emosi, sehingga mengarah ke tindakan yang buruk. Masa remaja adalah dimana masa peralihan dari masa anak-anak menuju dewasa. Pada masa ini terjadi perubahan secara biologis, hormonal, sosial, dan psikologis. Tingginya angka gangguan psikis bahkan hingga percobaan bunuh diri pada remaja disebabkan oleh kurangnya pengetahuan dasar mengenai kesehatan mental pada diri remaja sehingga mereka tidak sigap saat menghadapi gangguan mental yang ada pada dirinya maupun orang lain. Pada saat ini beragam media terutama media digital hadir untuk memberikan edukasi mengenai kesehatan terutama kesehatan mental dengan cepat dan tepat. Namun belum ada media seperti website yang menghadirkan edukasi mengenai kesehatan mental yang dikhususkan untuk remaja saja. Dengan permasalahan tersebut dibuatnya website edukasi kesehatan mental khusus untuk remaja dengan batasan materi gangguan mental yang umum pada remaja yaitu depresi, cemas, delusi, hingga percobaan bunuh diri. Diharapkan dengan adanya website ini remaja akan lebih teredukasi dan dapat menjaga kondisi mental diri sendiri maupun orang lain. Nilai lebih dari website ini adalah tampilannya sudah responsif sehingga cocok diakses via desktop maupun mobile, dan juga memiliki fitur meditasi untuk menenangkan emosional pengguna agar terciptanya tubuh dan jiwa yang rileks.

\section{PENDAHULUAN}

Kesehatan mental adalah sebuah kondisi dimana individu yang terbebas dari berbagai bentuk gejala-gejala gangguan mental. Individu yang sehat secara mental dapat berjalan dengan normal dalam menjalankan kesehariannya khususnya saat beradaptasi untuk menghadapi bermacammacam masalah yang akan ditemui sepanjang hidup seseorang dengan menggunakan kemampuan pengolahan stress (Putri, dkk. 2015). Bukan hanya kesehatan fisik saja, kesehatan mental pun merupakan hal penting yang harus kita perhatikan. Jika kesehatan mental seseorang terganggu, ia akan mengalami gangguan suasana di dalam hatinya, kemampuan untuk berpikir, dan kendali emosi yang mengarah pada perilaku yang buruk (Deswari, 2018).
Masa remaja adalah masa dimana seorang manusia sedang mengalami masa pubertas. Menurut WHO masa remaja adalah usia di antara $10-19$ tahun. Pada fase tersebut seorang remaja sedang terjadi perubahan yang pesat baik dalam fase biologis, hormonal, sosial, dan psikologis. Berdasarkan data Riset Kesehatan Dasar (Riskesdas) tahun 2018, prevalensi gangguan mental emosional pada remaja lebih dari 15 tahun sebesar 9,8 persen. Angka ini cukup meningkat jika dibandingkan dengan tahun 2013 yaitu sebesar 6 persen (Kemenkes, 2018). Remaja adalah masa peralihan dari anak-anak menuju dewasa. Seorang remaja sudah tidak lagi dapat dikatakan sebagai anak-anak, namun ia masih belum matang untuk bisa dikatakan dewasa. Ia sedang mencari pola hidup yang sesuai dengannya dan sering dilakukan bermacam cara walaupun melalui banyak kesalahan. Hal 
ini karena mereka memang sama-sama masih dalam masa mencari identitas.

Pada era digital serba cepat dan instan seperti sekarang ini banyak sekali media yang digunakan untuk memberikan informasi mengenai kesehatan mental dengan menggunakan bahasa internasional maupun Indonesia. Mulai dari aplikasi berbasis android/ios, video streaming, website, dan masih banyak lagi yang bisa kita temui di gadget yang kita gunakan sehari-hari. Dalam kondisi pandemi saat ini banyak remaja yang melakukan berbagai kegiatan dari rumah, tentunya lebih banyak menghabiskan waktu untuk berselancar di internet sehingga penggunaan media digital meningkat drastis. Asosiasi Penyelenggara Jasa Internet Indonesia (APJII) mencatat trafik internet atau data meningkat $20 \%$ selama pandemi per bulan April. Penggunaan media digital dinilai efektif untuk memberi segala informasi secara cepat daripada penggunaan media cetak yang sudah tertinggal zaman. Website adalah salah satu media digital yang banyak dipakai individu/organisasi dalam menyampaikan berita, pesan, informasi ke khalayak publik untuk dikonsumsi. Akses yang mudah dan tidak memakan banyak ruang di gadget, website menjadi media yang sering dipakai masyarakat untuk mengakses berita karena bisa diakses melalui desktop maupun mobile. Dibandingkan dengan aplikasi, website lebih ringan penggunaannya karena hanya mengandalkan browser atau mesin telusur yang sudah terpasang di perangkat android maupun ios untuk mengaksesnya. Namun, penulis sendiri masih merasa kurang dalam mendapatkan informasi mengenai kesehatan mental di suatu website yang masih terlihat kurang mencakup berbagai masalah gangguan mental dan tampilannya masih terlihat menggunakan versi yang sudah lama. Di zaman sekarang ini sudah ada penyegaran dalam dunia website yang menggunakan teknologi dan metode terbaru agar website terlihat responsif.

Dengan latar belakang dan masalah tersebut, penulis ingin menciptakan solusi yaitu dengan membuat media edukasi mengenai kesehatan mental bagi usia remaja SMA sederajat dalam bentuk website yang responsif dengan harapan para remaja masa kini bisa lebih meningkatkan minat, kesadaran, dan pengetahuan mereka mengenai kesehatan mental sehingga para remaja bisa mengetahui berbagai macam informasi tentang kesehatan mental, gangguan mental, cara mengelola emosi, dan lain-lain. Diharapkan juga para remaja bisa paham dengan situasi dan mau menolong orang di sekitarnya yang sedang mengalami masa sulit agar tidak melakukan sebuah tindakan yang tidak diinginkan. Saat ini memang banyak situs yang menyediakan informasi tentang kesehatan mental, namun situs tersebut dibuat untuk semua kalangan dari muda hingga tua. Situs yang hanya menyediakan informasi mengenai kesehatan mental bagi remaja yang penulis lihat di internet hanya ada dalam berbahasa Inggris. Sehingga penulis ingin membuat versi bahasa Indonesia agar bisa dibaca dan dipahami oleh remaja di seluruh Indonesia. Penulis memilih website karena bisa diakses dengan mudah dari perangkat desktop maupun mobile tanpa harus membuat aplikasi yang harus kompatibel dengan sistem operasi ios maupun android.

\section{TINJAUAN PUSTAKA}

\subsection{Website}

Menurut Abdullah (2015), website dapat diartikan sekumpulan halaman yang terdiri dari beberapa laman yang berisi informasi dalam bentuk data digital baik berupa teks, gambar, video, audio, dan animasi lainnya yang disediakan melalui jalur koneksi internet. Website atau situs ada yang bersifat statis maupun dinamis yang membentuk suatu rangkaian bangunan yang saling terkait, dimana masing-masing dihubungkan dengan jaringan-jaringan halaman atau biasa disebut hyperlink. Bersifat statis apabila situs tersebut memiliki isi informasi website yang tetap, jarang berubah, dan isi informasinya searah hanya dari pemilik situs. Dan bersifat dinamis apabila isi informasi situs selalu berubah-ubah, dan infromasinya interaktif dua arah yang berasal dari pemilik serta pengguna situs.

Website juga dibagi berdasarkan fungsi dan tujuan pembuatannya. Berikut adalah beberapa fungsi website yang paling umum.

1. Blog atau situs pribadi.

2. E-Commerce atau toko daring.

3. Website perusahaan.

4. Organisasi atau Instansi Pemerintah.

5. Media Edukasi.

6. Portal Berita.

7. Online Community.

8. Content Marketing.

Untuk menyediakan keberadaan sebuah website, maka harus tersedia unsur-unsur penunjangnya, diantaranya adalah:

\section{a. Nama Domain (URL - Uniform Resource Locator)}

Pengertian Nama domain atau biasa disebut dengan Domain Name atau URL adalah alamat unik di dunia internet yang digunakan untuk mengidentifikasi sebuah website, atau dengan kata lain domain name adalah alamat yang digunakan untuk menemukan sebuah website pada dunia internet. Nama domain diperjualbelikan secara bebas di internet dengan status sewa tahunan. Nama domain sendiri mempunyai identifikasi ekstensi/akhiran sesuai dengan kepentingan dan lokasi keberadaan website tersebut. Contoh nama domain berekstensi internasional adalah com, net, org, info, biz, name, ws.

\section{b. Rumah Tempat Website (Web Hosting)}

Pengertian Web Hosting bisa diartikan sebagai ruangan yang terdapat dalam harddisk tempat menyimpan berbagai data, file-file, gambar dan lain sebagainya yang akan 
ditampilkan di website. Besarnya data yang bisa dimasukkan tergantung dari besarnya web hosting yang disewa/dipunyai, semakin besar web hosting semakin besar pula data yang dapat dimasukkan dan ditampilkan dalam website.

\section{c. Bahasa Program}

Bahasa program adalah bahasa yang digunakan untuk menerjemahkan setiap perintah dalam website yang pada saat diakses. Jenis bahasa program sangat menentukan statis, dinamis atau interaktifnya sebuah website. Semakin banyak ragam bahasa program yang digunakan maka akan terlihat website semakin dinamis, dan interaktif serta terlihat bagus. Beragam bahasa program saat ini telah hadir untuk mendukung kualitas website. Jenis jenis bahasa program yang banyak dipakai para desainer website antara lain HTML, ASP, PHP, JSP, Java Scripts, Java applets dsb. Bahasa dasar yang dipakai setiap situs adalah HTML sedangkan PHP, ASP, JSP dan lainnya merupakan bahasa pendukung yang bertindak sebagai pengatur dinamis, dan interaktifnya situs (Suterimah, dkk. 2010).

\subsection{Kesehatan Mental}

Menurut Pieper dan Uden (2006), kesehatan mental adalah suatu keadaan dimana seseorang tidak mengalami perasaan bersalah terhadap dirinya sendiri, memiliki estimasi yang realistis terhadap dirinya sendiri dan dapat menerima kekurangan atau kelemahannya, kemampuan menghadapi masalah-masalah dalam hidupnya, memiliki kepuasan dalam kehidupan sosialnya. Kesehatan mental adalah keadaan dimana seseorang mampu menyadari kemampuannya sendiri, dapat mengatasi tekanan hidup yang normal, dapat bekerja secara produktif dan mampu memberi kontribusi terhadap lingkunganya (WHO, 2016). Kesehatan mental merupakan hal yang sangat penting bagi manusia sama halnya seperti kesehatan fisik pada umumnya. Dengan sehatnya mental seseorang maka aspek kehidupan yang lain dalam dirinya akan bekerja secara lebih maksimal. Kondisi mental yang sehat tidak dapat terlepas dari kondisi kesehatan fisik yang baik. Berbagai penelitian memberikan hasil bahwa adanya hubungan antara kesehatan fisik dan mental seseorang, dimana pada individu yang menderita sakit secara fisik menunjukkan adanya masalah psikis hingga gangguan mental. Sebaliknya, individu dengan gangguan mental juga menunjukkan adanya gangguan fungsi fisiknya. Sehat dan sakit merupakan kondisi biopsikososial yang menyatu dalam kehidupan manusia.

\section{HASIL DAN PEMBAHASAN}

Homepage adalah tampilan awal dari website edukasi kesehatan mental.

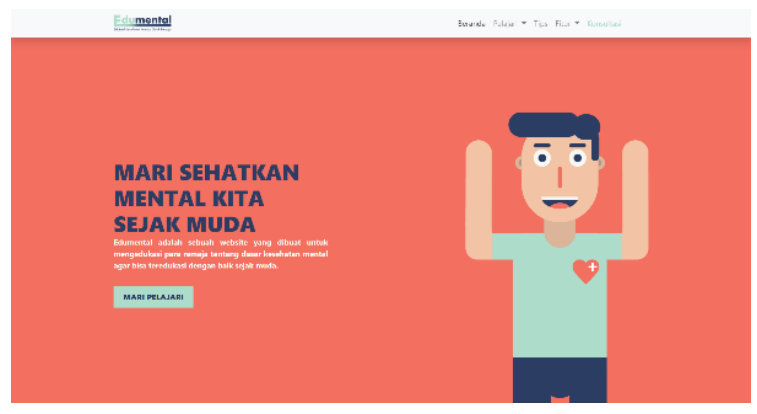

Gambar 1 Tampilan Awal homepage website
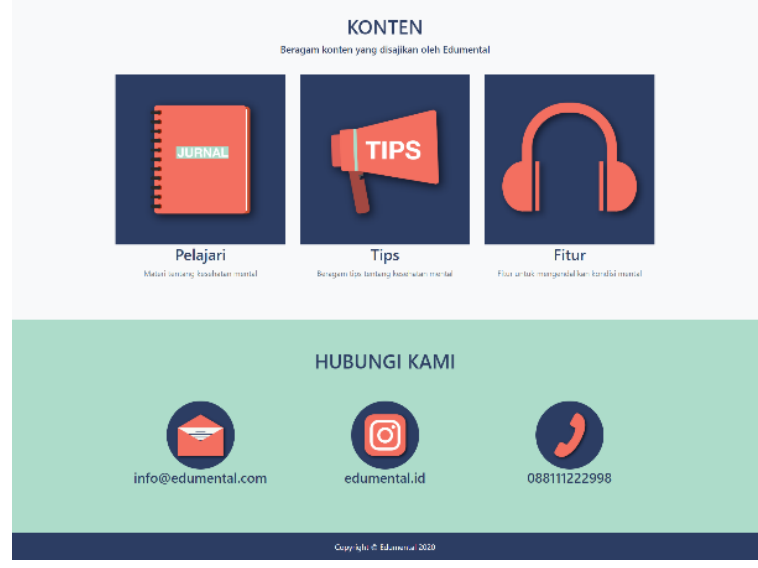

Gambar 2 Konten dan fitur yang disediakan website

Halaman artikel adalah halaman dimana dimuatnya sebuah teks dari artikel.

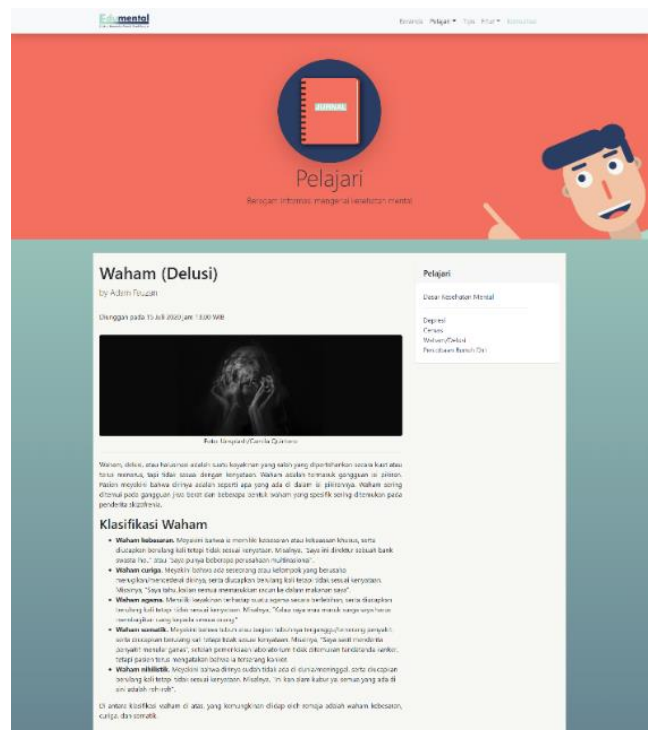

Gambar 3 Tampilan Halaman Artikel 
Halaman tips adalah halaman yang terdapat beberapa pilihan artikel mengenai tips dalam kesehatan mental.

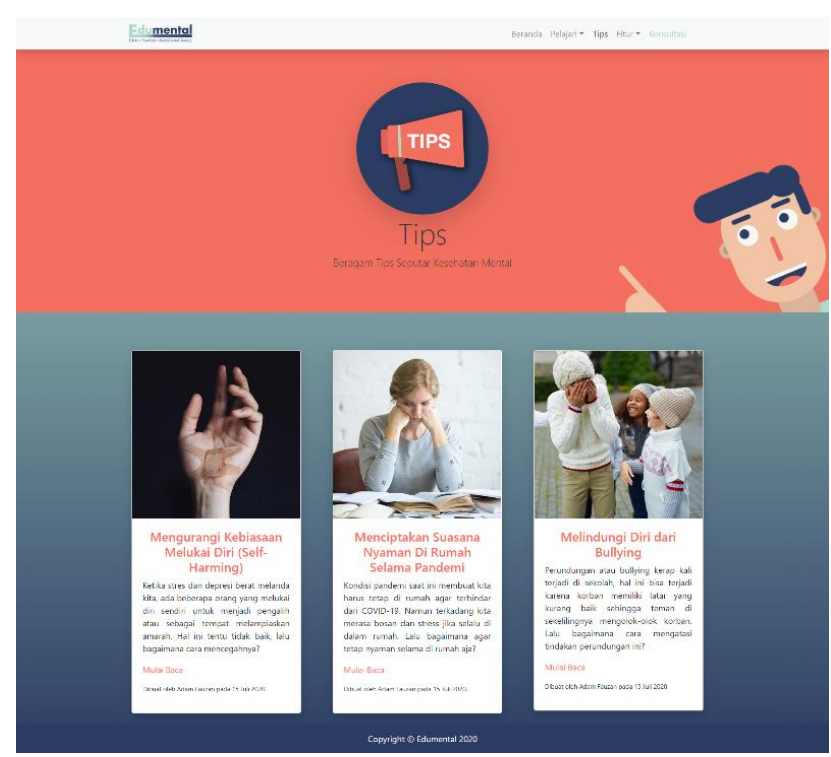

Gambar 4 Tampilan Halaman Tips

Halaman fitur relaksasi adalah sebuah halaman dimana fitur meditasi berada untuk merelaksasikan badan dan jiwa.

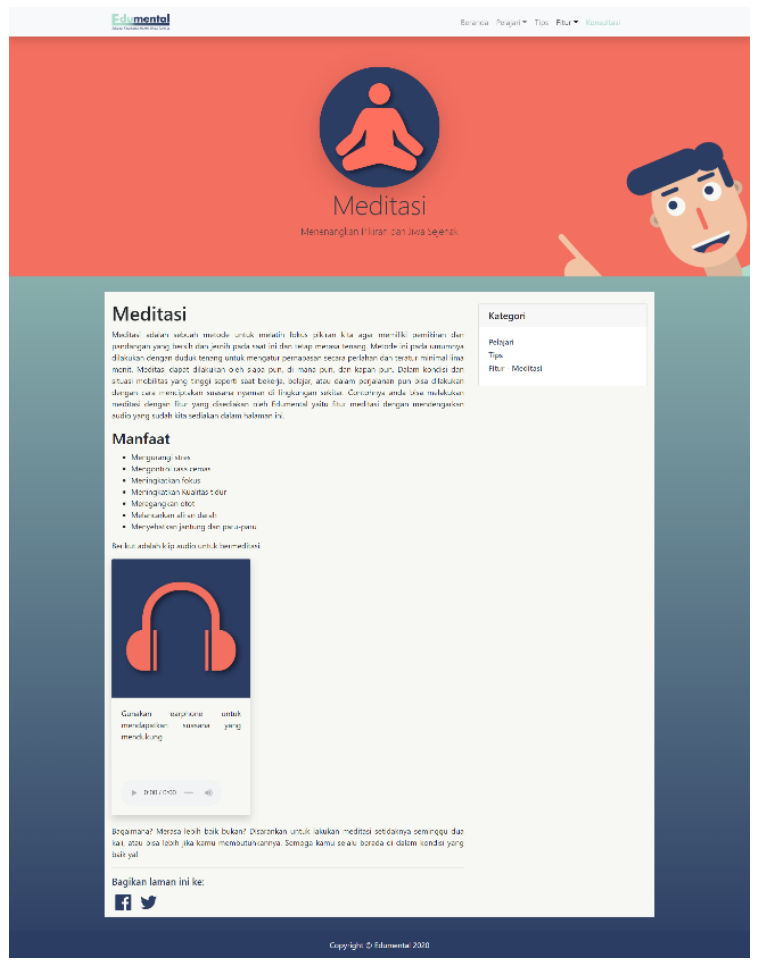

Gambar 5 Tampilan halaman relaksasi

Halaman konsultasi adalah sebuah halaman yang menampilkan pilihan tempat untuk berkonsultasi mengenai kesehatan mental.

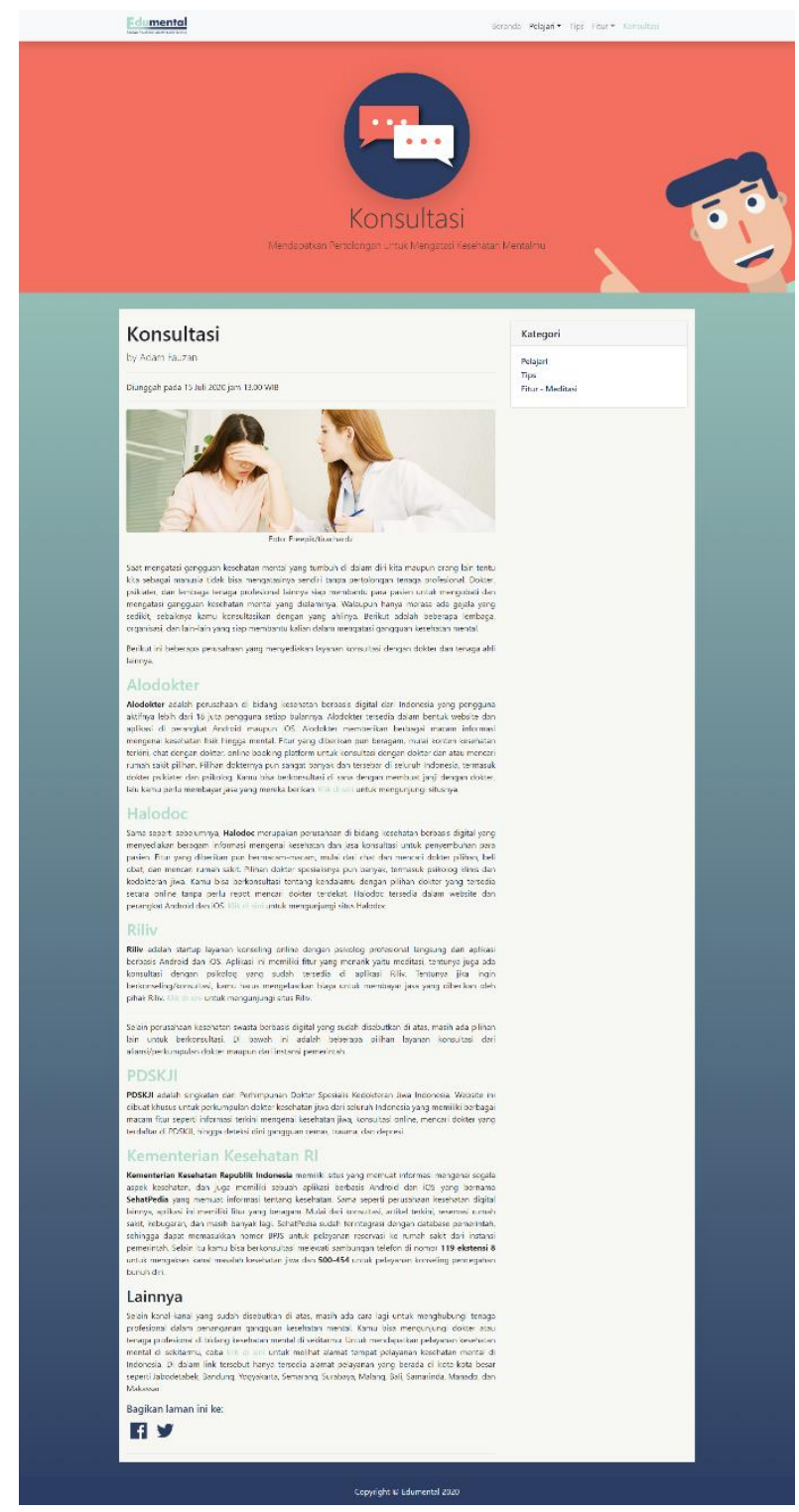

Gambar 6 Tampilan Halaman Konsultasi

\section{PENUTUP}

\subsection{Simpulan}

Simpulan dari karya tugas akhir tentang Pembuatan Website Sebagai Media Edukasi Mengenai Kesehatan Mental Bagi Remaja Usia SMA dan Sederajat adalah sebagai solusi atas masalah tidak adanya website edukasi kesehatan mental yang dikhususkan untuk remaja. Tambahannya yaitu website ini memiliki fitur meditasi sehingga pengguna dapat merelaksasikan tubuh dan jiwanya. Tahapan dalam membuat website ini mulai dari tahap melakukan pencarian tentang penelitian tentang kesehatan mental pada remaja, membuat konsep, pengumpulan data dan referensi, kemudian memproduksi aset gambar, video, audio, dan coding, lalu di tahap akhir menguji coba dan publishing. Pada tahap uji coba, sebenarnya tidak perlu memakai smartphone untuk menguji coba website tampilan mobile, cukup perkecil windows pada browser hingga selebar resolusi smartphone. Dari situ dapat dilihat bahwa website sudah responsif. 


\subsection{Saran}

Beberapa hal yang dapat dikembangkan dari website ini di antaranya adalah:

1. Setiap container pada halaman perlu diberi animasi transisi agar terlihat lebih menarik, sehingga website tersebut seperti professional website.

2. Menambah fitur seperti deteksi dini kecemasan atau depresi. Sehingga pengguna dapat mengetahui seberapa jauh tingkat gangguan kecemasan atau depresinya.

3. Memberi mini-test setiap materinya untuk melihat seberapa jauh pengguna memahami materi dari yang sudah disajikan.

4. Menambah fitur sebuah wadah untuk pengguna menciptakan artikelnya sendiri, sehingga website ini berkomunikasi secara dua arah (dari pemilik dan pengguna).

\section{DAFTAR PUSTAKA}

Dadan, S. et al. (2017). Kenakalan Remaja dan Penanganannya. Prosiding Penelitian \& Pengabdian Kepada Masyarakat. Vol 4, No 2, 128-389

Desi Hariyanto, K., \& Naryoso, S.Sos, M.Si, A. (2016). Pengaruh Intensitas Mengakses Fitur-Fitur Gadget dan Tingkat Kontrol Orang Tua Terhadap Kesehatan Mental Remaja. Interaksi Online, 4(2), 1-12. Retrieved from https://ejournal3.undip.ac.id/index.php/interaksionline/article/view/11318

Nurkhalisa, Deanita. (2019). Generasi Milenial dan Gangguan

Mental. http://news.unair.ac.id/2019/08/15/generasi-milenial-dangangguan-mental/

Putri, A. W., Wibhawa, B., \& Gutama, A. S. (2015). Kesehatan mental masyarakat Indonesia (pengetahuan, dan keterbukaan masyarakat terhadap gangguan kesehatan mental). Prosiding Penelitian dan Pengabdian kepada Masyarakat, 2

UNAIR News. (2018). Gangguan Kesehatan Mental dalam Belenggu Budaya Diam. http://news.unair.ac.id/2018/11/09/gangguan-kesehatanmental-dalam-belenggu-budaya-diam/

WHO. (2019). Adolescent Mental Health. https://www.who.int/news-room/fact sheets/detail/adolescent-mental-health. 